\title{
Uterine Corpus Carcinoma pT3a TNM
} Finding v7

National Cancer Institute

\section{Source}

National Cancer Institute. Uterine Corpus Carcinoma pT 3a TNM Finding v7. NCI

Thesaurus. Code C89565.

Uterine corpus carcinoma that involves serosa and/or adnexa (direct extension or metastasis). (from AJCC 7th Ed.) 